$23 \mid 2019$

101. Jahrgang

5. Dezember 2019

S. $1075-1114$

PVSt 2853

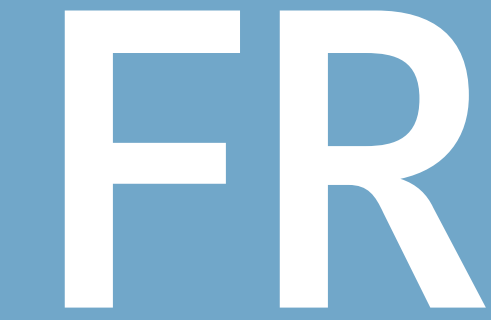

\title{
FinanzRundschau
}

Zeitschrift für das gesamte Ertragsteuerrecht

Herausgegeben in Verbindung mit dem Fachinstitut der Steuerberater

ertragsteuerrecht.de

Fachbeirat: RiBFH Prof. Dr. Andreas Herlinghaus · LMR Dr. Ingo van Lishaut · RA, StB Dr. Norbert

Schneider · StB Prof. Dr. Andreas Schumacher - Univ.-Prof. Dr. Roman Seer

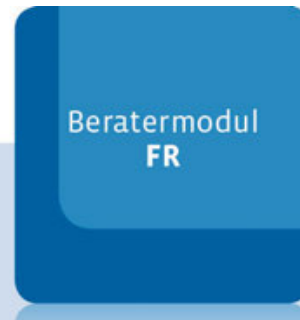

Nutzen Sie jetzt Ihre Datenbank!
Aufsätze > Klaus-Dieter Drüen - Verfahrensverschränkungen und Rechtsschutzfolgen im Lohnsteuerverfahren (Teil II)

Mirco Zantopp - Neues zum gesonderten und einheitlichen Feststel-

lungsverfahren in Fondsstrukturen 1085

Rechtsprechung > Auf den Anteilstausch entfallende Wertsteigerung - Veräußerung der bei dem Austausch erhaltenen Anteile - In der Besteuerung aufgeschobene Wertsteigerung (EuGH, Urt. v. 18.9.2019 - C-662/18 und C-672/18) m. Anm. Norbert Dautzenberg

Abfindungsklausel und Eindeutigkeitsgebot

(BFH, Beschl. v. 10.7.2019 - XI R 47/17)

Abfindungsklausel und Eindeutigkeitsgebot

(BFH, Urt. v. 23.7.2019 - XI R 48/17) m. Anm. H. Weber-Grellet 1104

Grundstücksenteignung kein privates Veräußerungsgeschäft i.S.d.

§ 23 Abs. 1 Satz 1 Nr. 1 EStG (BFH, Urt. v. 23.7.2019 - IX R 28/18)

m. Anm. H.-J. Kanzler 1109

Verwaltungsentscheidungen > Elektronische Lohnsteuerabzugsmerkmale (ELStAM); Abruf der Lohnsteuerabzugsmerkmale im ELStAM-Verfahren für gem. $\$ 1$ Abs. 4 EStG beschränkt einkommensteuerpflichtige Arbeitnehmer ab dem 1.1.2020 (BMF, Schr. v. 7.11.2019 - IV C 5 - S 2363/19/10007:001 - DOK 2019/0972167) 


\section{Fiktiv selbständig?}

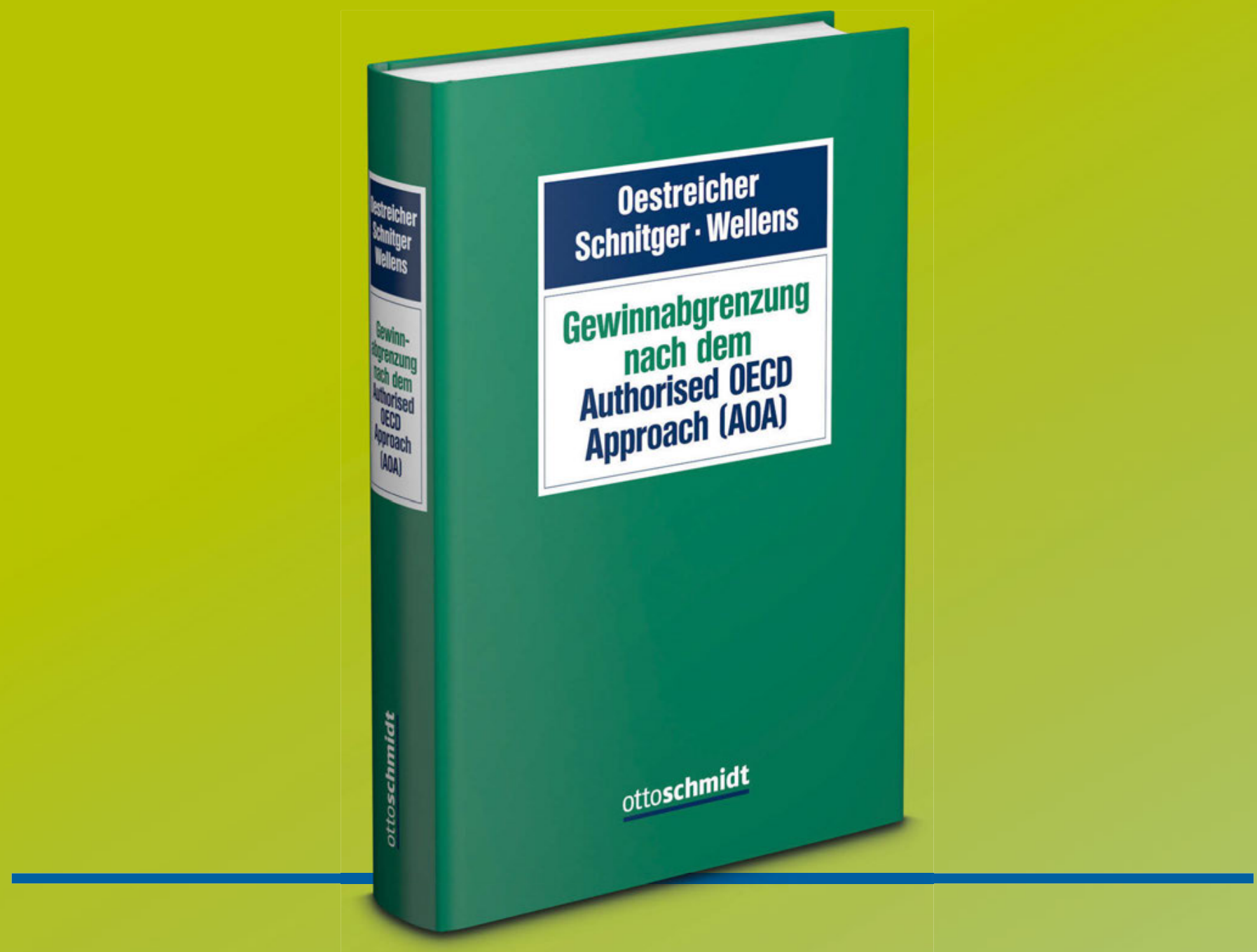

Das neue Handbuch bietet eine lösungsorientierte Auseinandersetzung mit dem rechtlichen Rahmen und den einzelnen Regelungen der Betriebsstättengewinnabgrenzung nach dem Authorised OECD Approach (AOA) in Deutschland. Es versetzt den Praktiker in die Lage, die Herausforderungen zu meistern, die sich aufgrund der Implementierung des AOA im deutschen Steuerrecht stellen. Die entsprechenden Vorschriften werden systematisch dargestellt, praxisbezogen analysiert und anhand von Beispielen erläutert.

Oestreicher/Schnitger/Wellens, Gewinnabgrenzung nach dem Authorised OECD Approach (AOA). Herausgegeben von Prof. Dr. Andreas Oestreicher, Dr. Arne Schnitger, Dr. Ludger Wellens. Bearbeitet von 18 Experten aus Beratung, Unternehmen, Finanzverwaltung und Wissenschaft. 2020, ca. 800 Seiten Lexikonformat, gbd. ca. 200,00 €. Erscheint im Frühjahr 2020. ISBN 978-3-504-26106-1

Am besten gleich vorbestellen unter www.otto-schmidt.de/aoa 